\title{
Reflections on Being a Learner: The Value of Relationship-based Community Evaluations in Indigenous Communities
}

\author{
Gerald McKinley \\ Western University
}

\begin{abstract}
Drawing on Donna M. Mertens and Amy T. Willson's work on transformative paradigms in program evaluations, together with the author's experience working in partnership with First Nations communities in Ontario, this paper explores the lessons learned from the process of moving between assumptions and application using the transformative paradigm in First Nations evaluations; explores the relationships between power, discourse, and paradigms in the relationship between Western and Indigenous ways of knowing and being; and asks what steps an can evaluator take to ensure that local epistemological and ontological perspectives are respected and captured.
\end{abstract}

Keywords: Canada, discourse, Indigenous, power, relationship-based, transformative paradigms

Résumé : Cet article s'appuie sur les travaux de Donna M. Mertens et d'Amy T. Wilson portant sur les paradigmes de transformation sociale en évaluation de programme, ainsi que sur l'expérience de l'auteur qui a travaillé en partenariat avec des communautés des Premières nations de l'Ontario. Il décrit certaines leçons tirées de l'application du paradigme de transformation sociale lors d'évaluations en milieu autochtone, tout en explorant les relations entre le pouvoir, le discours et les paradigmes occidentaux et autochtones. L'article présente également une réflexion sur les mesures qu'un évaluateur ou une évaluatrice peut prendre pour s'assurer que les perspectives épistémologiques et ontologiques locales soient respectées et prises en compte.

Mots clé : Canada, discours, autochtone, pouvoir, fondé sur les relations, paradigmes de transformation

One of the greatest benefits and unnerving experiences of being a communitybased researcher is having our way of seeing the world changed. Sometimes the process includes having our assumptions dismantled in front of us. Other times the process is a slow and growing appreciation for a new perspective. This paper

Corresponding Author: Gerald McKinley; Department of Pathology and Laboratory Medicine, Western University, 1465 Richmond Street, London, Ontario N6G 2M1; gmckinl@ uwo.ca 
reflects my experience with personal and professional paradigm shifts. The paper is part of my continuing journey as a learner working with First Nations people, mostly Anishinaabek, in southwestern and northwestern Ontario. I am not an Indigenous person. I am immigrant from Northern Ireland, part of a settler tradition. Additionally, I do not use the term ally to describe myself. Instead, I continue to use the term "learner" to reflect the humility that I have been taught is necessary for the applied, relationship-based research that I do. I came to the process of evaluation through relationships and need rather than through my formal education. I bring a background in multi-disciplinary research to this paper, which draws on the disciplines of social sciences, humanities, and qualitative mental health methodologies. In the past few years I have been engaged as a community-based partner in child and adolescent mental health programs in several communities. During this time, it has become increasingly obvious that program evaluations play an important role in transforming and developing community-based programs. This paper will draw on what I continue to learn, from the process of working with my partners and teachers. Specifically, evaluations have been crucial for understanding the gaps that continue to exist between Western and Indigenous ways of knowing the world. As I continue to learn more about the complexity of Anishinaabek epistemology and ontology, I am growing to understand how evaluations can articulate complexity to funders and government policymakers in language that they understand.

Reflecting on the work of Christopher Keane (1998), I argue that at the most fundamental level, the concept of "health" can be assumed to be a normative understanding of how a society should be structured, which is maintained in powerful discourses. Working with this position, I further argue that we must be aware of the assumptions we place into the narratives we produce during the process of evaluation. This argument assumes that evaluations can carry an underlying normative exploration of the ability of a community to carry out activities that lead to health and that it is this normative aspect which determines merit, worth, and value. On the topic of merit, worth, and values, Donna M. Mertens and Amy T. Wilson (2012) ask where the criteria for evaluations come from and what they are derived from. This question serves to guide me in this paper as I consider the work I do with Indigenous communities across Ontario. This position leads me to question if an evaluation is a tool of normativity or whether we can speak to the power of established paradigms through new narratives? With this in mind, I ask if we can make meaningful advances in our willingness to accept Indigenous perspectives at a time when we, as a society, are engaged in a process of truth and reconciliation. Ultimately, I ask if program evaluations play a role in shifting existing paradigms of health through a process of community engagement.

Applying a critical ethnographic lens, this paper explores my experiences learning from the process of conducting evaluations on community-run, Crownfunded programs in Anishinaabek communities. In doing so, I reflect on my ability as an evaluator to create narratives that reflect the values of the community and measure the effectiveness of the program in ways that do not reduce Anishinaabek 
knowledge to tropes of "Indianness." Drawing on medical anthropology and the work of Mertens, which "prioritizes issues of social justice and human rights as overarching principles" to form the basis of any evaluation (Mertens, 2013, p. 27), this paper will explore

1. the lessons learned from the process of moving between my assumptions and application using Mertens's transformative paradigm in First Nations evaluations;

2. the relationships between power, discourse, and paradigms in the relationship between Western and Indigenous ways of knowing and being; and

3. the steps an evaluator can take to ensure that local epistemological and ontological perspectives are respected.

I ask the reader to consider the concepts of "health" and "healthy community." From a theoretical position, my approach to the relationship between normativity and a social construction of what a healthy community looks like is based on work by Christopher Keane. In his paper "Globality and Constructions of World Health," Keane (1998) makes two important arguments: first, we must consider our world as a system of societies where discourse about health establishes the meaning of the concept of health; second, an examination of the social construction of health will uncover multiple ideological discourses on how our societies can and should be structured. The power of discourses to shape normativity and thus create paradigms is important when we include the role of assumptions for a paradigm shift as called for by Mertens. I assume that discourses, particularly discourses located in power, maintain established paradigms and their normative expectations. Recall that Merten's transformative paradigm responds to Thomas S. Kuhn's theory of the scientific paradigm (Mertens, 2009, p. 255). Kuhn was interested in normative perspectives and meanings within scientific discourse and focused on how changes in meaning signalled or were required for a shift in worldviews associated with scientific knowledge (Keller \& Lloyd, 1992, p. 2). However, if, as Mertens (2009, p. 44) contends, members of a dominant culture continue to use language that contains culturally influenced terms that can exclude members of non-dominant cultures from the meanings held in the discourse, the consequence is that transformative actions are responding to "established" evidence and discourse in our attempts to engage in paradigm shifts.

It is through Mertens's work that I hope to articulate the movement between theory and action. My end goal is to situate my role in the process of program evaluation within existing power structures and to see how I can apply evaluations and the authority I hold to be a tool for change. I do this to demonstrate how the process of learning from our community partners is an important step in the process of reconciliation. I will show through my applied experiences how an Indigenous concept of health that was once silenced can be voiced and valued within the existing power relationships to privilege Indigenous knowledges. Drawing 
from Ronald Labonte and Renee Torgerson (2005), I consider the concept of a community as one level in a complex system. In this way, I remain theoretical but ground that theory in practical experience in order to see how change may happen.

\section{THE NORMATIVE CONTEXT OF THE EVALUATION NARRATIVE}

Keane (1998) argues for the existence of a normative discourse in health research. "Normative," in the context of this paper, is assumed to be a set of standards that establish current or dominant paradigms and that are maintained through existing discourses. Existing normative discourses can include forms that promote an ongoing focus only on negative health outcomes instead of being open to resilience and positives; or narratives that continue to promote damaging beliefs in the idea of an Indigenous monoculture in the place of the complexity that exists within diverse Indigenous populations. All of these narratives are false but take on the role of the simulacra where the story replaces reality (Baudrillard, 1983). As a result, there are important consequences that must be considered when one is engaged in evaluations that will challenge existing dominant paradigms. If, as Keane suggests, we articulate health as an ideologically bound vision of how the world should look, do we risk writing over First Nations narratives of wellness? Do we truly value Indigenous research methods within the academy, or are we in a constant process of translating them into accepted scientific models? Or do we continue to deny intellectual and local "sovereignty when it conflicts with what colonists and modern-day corporate or nontribal government partners" expect (Waapataneexkweew, 2018, p. 550)? How does a society value Indigenous knowledge during the process of reconciliation? Much of what I will argue in this paper works from the position that in order to enact meaningful change, we must work beyond dominant theoretical constructs and change the discourses that maintain powerful Western paradigms on health.

The transformative paradigm approach works to break down these discursive barriers by focusing on assumptions in four key areas: reality (ontological), the nature of knowledge (epistemological), the approach to systematic inquiry (methodological), and ethics (axiological) (Mertens, 2009, p. 45). Assuming that evaluations are a measure of the merit and worth of a program, then we need to be concerned about how we tell the story of the program we are evaluating, how we access information, what we do and do not share, and what that interpretation of data means (Mertens \& Wilson, 2012, p. 6).

I frame my argument and its connection to the transformative paradigm using two examples. The first comes from thinking about "what is," with the conception of structural violence being a case in point. I draw on Paul Farmer's efforts to connect structural violence with health services. Farmer (2004, p. 307) notes that "structural violence is violence exerted systematically-that is, indirectly-by everyone who belongs to a certain social order." It is violence that does not depend on a single actor but instead exists at the systems level: the levels of privilege and inequality that benefit some while creating disadvantages for others. It is the 
system that Mertens wrote about in Kentucky in the 1960s as a child, which was explained away as the way things are (Mertens \& Wilson, 2012, p. 161). As a social mechanism, "structural violence is embodied as adverse events [and] is the experience of people who live in poverty or are marginalized by racism, gender inequality, or a noxious mix of all of the above" (Farmer, 2004, p. 308). Farmer holds that structural violence is, in part, dependent on the creation of a hegemonic narrative of history that legitimizes the system of inequality (Farmer, 2004, p. 308).

The current health inequalities facing First Nations people in Canada can align with this definition of structural violence. Current government policy and actions are not isolated ahistorical events. Instead, they are part of a long history that connects the health and wellness of Indigenous populations in Canada to Indigenous populations around the world via economic, political, and social policy. Before Canada existed as a state, it was a colonial appendage for England and France. The Staples Theory developed by Harold Innis holds that Canada has developed into its current economic, political, and social form because of the exploitation of a changing series of staples, including fish, fur, lumber, minerals, oil, and gas (Breau, Toy, Brown, MacDonald, \& Cooms, 2018, p. 357). The administration of "Indians" by the Crown through this history, which continues through ongoing consultations and actions around minerals, oil, and gas, is about ensuring market access to staples rather than the welfare of a population. The Royal Proclamation of 1763, which is now enshrined in the Canadian Constitution Act, 1982, established a Nation-to-Nation relationship between the Crown and Indigenous peoples. Policies such as the Indian Act, Indian residential schools, and the selling of reserve land are an abuse of the fiduciary responsibility that the Crown adopted in the relationship and perpetuate the social inequalities that legitimize stereotypical views of Indigenous populations. Kirmayer, Gone, and Moses (2014) argue that these actions represent ongoing structural violence rather than past traumas that contribute directly to the health of Indigenous peoples in Canada.

My second example focuses on transformation. It is grounded in the global health model developed by Labonte and Torgerson (2005). As shown in Figure 1, the model acknowledges bidirectional connections between policy and action at multiple levels, which run from individual to superordinate categories. The model is important for understanding the transformative paradigm because it helps to locate our own actions and any potential connections across actors. The interconnected model allows me to think about how the economic, political, and social policies and the power that maintain a system of inequalities are connected to the communities I work in. By understanding these connections, I am better able to speak back against them. The modelling of a complex system allows for targeted steps within its mechanisms to voice connections to global policy and trade over simplistic assumptions of "that's just the way they are."

The production of an evaluation is, in its most basic sense, the creation of a narrative. As the authors of these narratives, we, the evaluators, make choices that are inherent in the power that we hold (Scriven, 2017). From the choice of methods to the design of our questions, to the outcomes on our logic models, we 


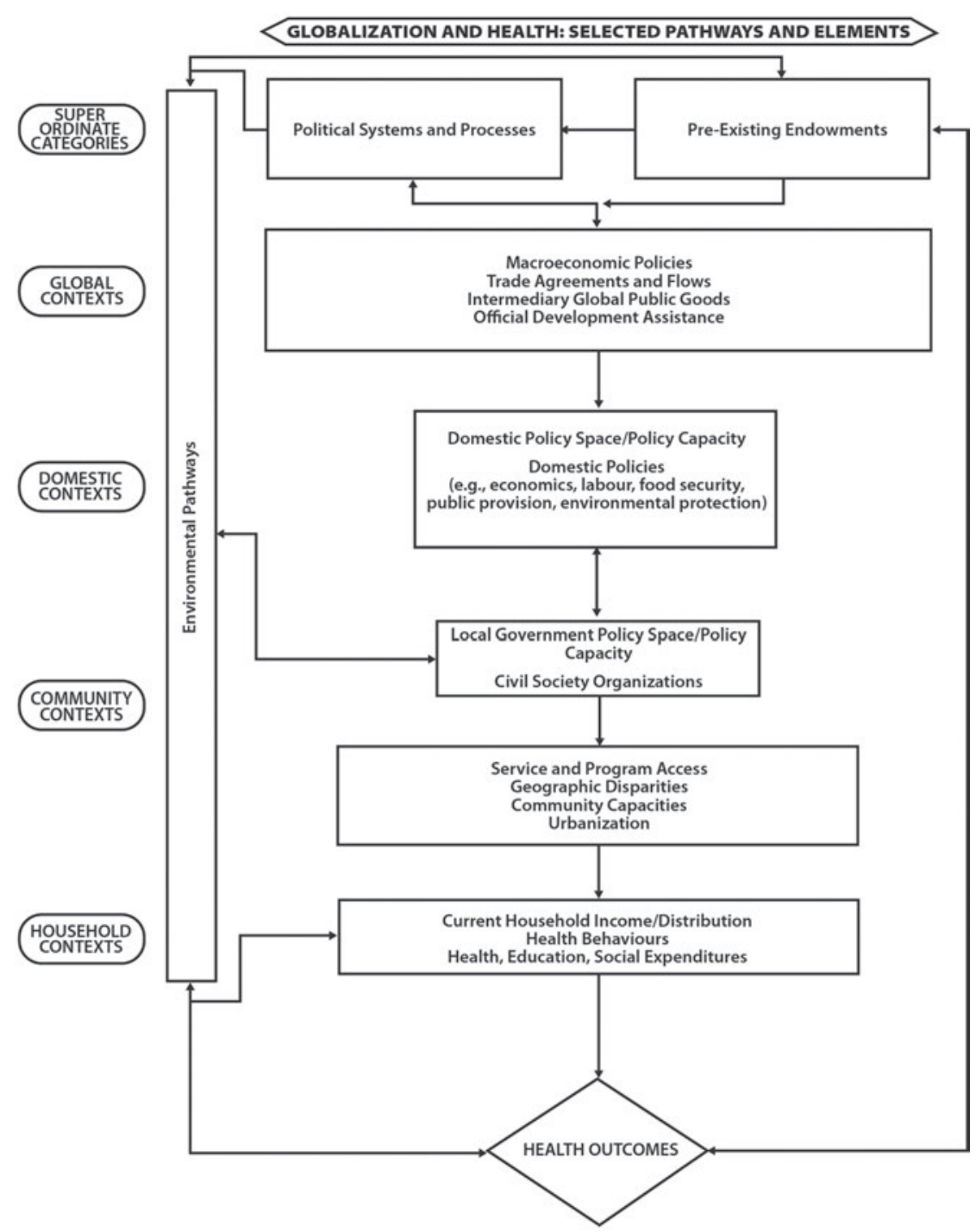

Figure 1. Globalization and health basic framework

are figuring out how to tell a story, which characters to use, and if that story will be a positive or a negative one. The power we wield becomes more important for us to recognize when we work with communities that are traditionally marginalized or silenced.

In the context of completing evaluations of Crown funded programs in First Nations communities, these powers can be accentuated. Consider the word "health" as a concept. The WHO definition is well known: "a state of complete 
physical, mental and social well-being and not merely the absence of disease or infirmity" (International Health Conference 20027). In the English language, health is a state, a noun; however, in Anishinaabeemowin, the language of the Anishinaabek, there is no word for health. There is a word for a concept of living a good way: bimaadiziwin, which is based on the verb for "be alive": bimaadizi. The distinction between a noun and a verb may seem small, but it is in language use that all events are converted into narratives. Having health be understood as something we do rather than something we have is important for the narrative. The difference in language harkens to the power of dominant groups to assume that everyone understands how they are speaking. Living a good way has important ontological implications and ties how we view knowledge, ethics, and data collection.

The process of understanding the connection between discourses that maintain structural inequalities and how program evaluations fit into a larger global system starts with ourselves. Within that in mind, I shift my attention to a case study demonstrating the application of the transformative paradigm. The purpose of the application is to demonstrate the bidirectional movement between theory to action within a larger context.

\section{CASE STUDY}

Between fall 2017 and fall 2018, I was actively engaged in the evaluation of an education-based program in a First Nation community in southwestern Ontario. It is a community that I have worked with for a number of years and where I continue to be mentored. Because the report was ultimately destined for Health Canada, my community partners and I decided to follow the evaluation guidelines set out by the Ontario Centre for Excellence for Child and Adolescent Mental Health (OCECAMH). The process of organizing the evaluation demonstrated the importance of trust in relationships that take years to grow. Working in multiple communities, I have learned that best practices in maintaining trust start with open communication. Through this process, the OCECAMH guidelines were determined to be flexible enough to allow local community values to be prioritized. It is an error to assume that resources originating outside of a First Nations context should be rejected outright. Instead, consultation and the accepting of our responsibilities in relationships allows us, as evaluators, to bring additional advantages to our partners. Unilateral application without a relationship reinforces power imbalances. However, ongoing consultation is an effective means of decentring power away from our institutions.

Early site visits with program administrators were used to develop an understanding of the structure of the program. These meetings also served as early stakeholder-engagement sessions. Because of the small size of the immediate program team, early stakeholder engagement was a relatively efficient process. Inperson, one-on-one meetings allowed for the effective development of key evaluation questions. The sessions aided in the development both of search topics for the literature review and of the logic model. Stakeholder meetings, the literature review, and the logic model were then used to identify quantitative and qualitative 
outcome measures. An online survey and focus group interviews were identified as methods for qualitative data collection.

The program provided in-school services for at-risk youth who, under regular conditions, are at elevated risk of not completing secondary school. The staff were trained in crisis intervention and were able to de-escalate situations safely and effectively. Services provided include access to social workers, psychological counselling, speech and language pathology, and occupational therapy. The program also brings traditional healers into the school in order to incorporate local Anishinaabek teachings into the school day. Overall, the program reduced total school suspensions by three quarters, increased graduation rates, and decreased crisis situations in school. The effects extended beyond the students enrolled in the program by making the school safer overall.

The learning for me came in articulating the "why" of the program. The program was supported and valued highly by students, staff, the families of students, and professional health-care providers who worked with the program. Quantitative data told only a small part of the story; the real value of the program was found in in-program relationships. Among many Anishinaabek people, relationships are of great importance. The funder of the program was comfortable with the quantitative data. The funding was to make the school safer and increase graduation rates. That job was done. However, in conversation with community members, it became clear that they wanted the evaluation to reflect Anishinaabek values such as the Seven Grandfathers' teachings. The program has become a source of pride for many involved with it, and it was clear the more I worked with participants that they viewed the human resources and the Anishinaabek values used in the program as the reason for its success.

Based on the Labonte and Torgerson (2005) model, the interactions between levels of power start to become evident. The top-down funder expected results from the evaluation that reflected their normative understanding of value, merits, and worth. Community-level expectations, particularly from the host department in the community, reflected another set of values, including the impact of the program on local families. At the individual level, the role that each participant played in the program affected their expectations of normative values. It is in this interaction between levels that the transformative paradigm is important. If an existing construct of a paradigm contains within it a set of theories, and the theories are ways of thinking about the social construct that is the paradigm, changing the theory does not necessarily change the paradigm (Mertens \& Wilson, 2012, p. 34). What is needed, then, is a way of changing the paradigm to engage with the concept of "health" as a verb (bimaadaziwin), rather than remain rooted in the WHO definition.

If we recall that Mertens drew on Guba and Lincoln's (1989) definition of paradigm as consisting of the four philosophical assumptions of ontology, epistemology, methodology, and axiological (Mertens \& Wilson, 2012, p. 36), the transformative paradigm then provides a means of exploring the larger picture that is the interaction of power, and power imbalances, in a multi-level system. It is here that I return to the importance of discourse in this argument. Paradigms 
are social constructs, which can be transmitted between people only through language, and, to stick with a strict definition, discourse is defined as any use of language longer than a sentence. Here, the importance of the distinction between health as a thing versus health as an action becomes important. In the case study, I initially was interested in the outputs that the program produced in the form of better quantitative data. However, the lesson was that the community valued the way in which people behaved. Therefore, two paradigms, one evaluation report.

\section{THE IMPORTANCE OF ONTOLOGY}

Mertens (2009) defines ontological assumptions as being socially constructed and notes that the social construction is based on a foundation of unequal power distribution. Power is a function of politics, economics, gender, culture, and ethnicity, to name but a few. Power and social forces, then, are an assemblage of factors. However, it must be considered as a fluid system of interactions, not a mere spectrum from powerless to powerful. Returning to Mertens's quote about the state of schools in Kentucky, it is power that allows a social inequality to be articulated as "just the way things are," but, I add, there is also power in evaluation to change how we approach those things.

The ontological assumptions are an important place to start when articulating my experiences working with First Nations communities. The nature of being, or of being a spiritual being experiencing a physical existence, will affect the other three aspects of Mertens's transformation paradigm. The assumptions that I carry with me from my experiences as a non-Indigenous person can lead to invalid conclusions about the processes or effectiveness of a program. Factors such as politics, economic development, or culture play a much smaller role in my day-to-day life than they do in the functioning of the communities where I have relationships. In using the term "culture," I do not wish to suggest that First Nations peoples are culturally bound: that would be an error. In Labonte and Torgerson's (2005) model, culture functions differently at the individual, community, and government levels. We are all multicultural in the sense that we are all disciplined through various forms of education (home, school, work, larger social settings, etc.). To say someone is Anishinaabek, for example, should not circumscribe them into a narrow understanding of what that means, for the same person may also live the culture of a physician or a hip-hop fan. Instead, I argue that we should consider culture as a guideline for how we as individuals and communities manifest different cultures (Mertens, 2009, p. 62).

The first assumption that can be considered when working in First Nations communities is the nature of the self. It is clear that all societies and all cultures have ways of understanding, or questioning, what it means to be a being in this world. Interestingly, for many cultures their own name for themselves as a people is often translatable as "the people." I am fortunate to have the opportunity to continue to learn from communities mostly consisting of Anishinaabek people in Ontario. One thing that has become clear is, regardless of whether individuals 
consider themselves to be traditional or Christian or somewhere in the middle, for many the self still retains a significant aspect of responsibility-based actions.

The idea of responsibility-based, community-focused rather than deliverablefocused action is challenging to evaluate as a researcher. Largely it comes down to the scope of our evaluation and the interconnected layers of the community. One of my community-based teachers refers to projects in a quilt-like fashion. They all connect for the community. If our scope is limited to a single project, we lose sight of the quilt and of other responsibilities that our partners have. The scope, or scale, of the evaluation will reflect the different degrees of complexity that are present in a program (Mertens \& Wilson, 2012, p. 17). But this complexity can be lost if we are circumscribed by funder limitations on the scope of the program, which are usually concerned with accountability for spending.

A second key ontological element is that of language connotation. The nature of Anishinaabemowin is that where you are and who you are speaking with will affect how the language is structured (Valentine, 2001). It is a largely verb-based language providing an important context/place link. While the use of Anishinaabemowin has declined, it continues to influence how people speak English in Anishinaabek communities. It is in local connotational values that I have had an opportunity for the greatest learning and have made some of my greatest mistakes. The connection between what a word means and where you come from cannot be overstated. For example, I learned very early that having a $\mathrm{PhD}$ and being a university faculty member was not overly important to my community relationships. More importance is placed on how I act with humility and kindness than to titles that I hold. Social capital and the power that comes with it are assigned differently in First Nations contexts.

\section{EPISTEMOLOGICAL ASSUMPTIONS}

In Mertens's transformative paradigm, epistemological assumptions focus on the nature of knowledge and how the relationship between the researcher and partners is developed in order to understand the context of the research (Mertens, 2009 , p. 56). Working with First Nations partners has demonstrated that the relationship and trust aspect are most important. The action of building relationships ties the epistemological assumption to the ontological. When we engage in building relationships, we assume a set of responsibilities within that relationship. In addition, the quality of these relationships helps establish the quality of the evaluation itself (Mertens \& Wilson, 2012, pp. 44-45). In an Anishinaabek context, relationships and responsibility are essential aspects of bimaadiziwin.

We are, as evaluators, also in a relationship with our knowledge systems. We socially acquire our understanding of knowledge systems during the process of disciplining ourselves in the education system. Positivist and post-positivist notions of neutral and objective researchers are greatly problematic and potentially damaging to the process of relationship building. With this in mind, the first epistemological assumption that I reflect on is that theory is external to the 
community; it is an academic preoccupation. As discussed by Mertens and Wilson (2012), theories are contained within our paradigms. Our actions in evaluation are influenced by program theory, evaluation theory, and social science theory (Mertens \& Wilson, 2012, p. 34). And while there are some excellent and important theoretical approaches, we must consider the manner in which the narratives in our own reports are created. We all carry biases, positive and negative, which will influence how we construct the narrative of the report. On this, Mertens (2009, p. 175) argues that bias apply to all methods and can affect our choice of categories and variables for quantitative evaluations. For example, numbers, valued for their objective narrative of things, are little more than a language. Our bias in defining terms shapes what the numbers say. For example, a tool measuring resilience might provide a numerical representation of resilience, but a personal story of resilience captures another aspect. Our bias or preferences dictates how we value each.

The school-based program aims to keep students in school by implementing a proactive approach similar to the Collaborative and Proactive Solutions (CPS) program developed by Ross Greene (Greene \& Winkler, 2019). CPS includes students and the context of their lives in building proactive solutions in response to what were traditionally seen as behaviours requiring discipline. The approach is time-intensive and slower relative to the "safe schools" approach. With the safe schools policy, schools are expected to take a zero-tolerance approach to violence in school, regardless of the context of the violence (Daniel \& Bondy, 2008). My training in the social etiology of mental illness and my own ideological position inform me that the CPS approach is more likely to produce a positive outcome for the student. However, if I believed in the benefits of punitive response, my evaluation of the program would take a different form. My theoretical approach to the narrative could influence the future of the program, its funding, and its leadership.

The second assumption I work with is that the complexity of local knowledge is best understood in the context of the community. However, that context should be considered within a scope of relationships. The community context does not mean setting up boundaries around the geographic site of the community. Instead, it asks us to consider how flows of information and relationships are interpreted and acted upon within that setting. For example, Dean Jacobs, consultation manager at Walpole Island First Nation, speaks of the need to view the community in terms of the local ecosystem, the larger Great Lakes ecosystem, and the continental ecosystem (Jacobs, Darnell, \& McKinley, forthcoming). Local knowledge must be considered as an essential component to research/evaluation programs.

With that in mind, my experiences have been that local knowledge is not always scalable and requires a knowledge translation approach that responds to this challenge. During the development of a child and adolescent mental health program in a smaller Anishinaabek community in the near north of Ontario, our team set out to build relationships for a successful program. During this process, it became clear that program ideas that focused on teaching land-based or hunting 
skills would not be appropriate because the youth were already skilled in this area. This contrasted with our observations in other communities, where youth tended to exhibit few land-based skills. The connections between community members that develop on the land were already in place in this particular context. Instead, through a process of listening and sharing, a program built on what we called "responsibility-based" actions was built. During the evaluation process, it became clear that the team's willingness to listen and learn about local knowledge was an important factor in the success of the program.

\section{METHODOLOGICAL ASSUMPTIONS}

Mertens's transformative paradigm does not have a set list of methods that she recommends. Instead, it focuses on the establishment of a "philosophical basis" that can guide the development of a protocol, usually through mixed-methods approaches (Mertens, 2009, p. 59). For my own purposes, I utilize the program evaluation toolkit published by the Ontario Centre of Excellence for Child and Mental Health (2013). The stepped program in the toolkit works effectively with the community-based knowledge translation approach that I will discuss shortly. It allows for a natural back and forth between community and researcher/evaluator, thus helping to reduce the degree of invisible normative assumptions that can find their way into an evaluation.

The first major assumption that I work with is the need to focus on assets rather than deficits (Waapataneexkweew, 2018). This is an appropriate place to return to narratives and their power to create. Consider how Indigenous health is discussed in Canada (and globally). Based on a history of division and marginalization, there remains a tendency to focus on what is lacking or damaged in First Nations communities: drinking water, housing, food security, to name a few. Crengle et al. (2014) call for the development of measures that focus on the development of strengths, knowledge, skills, and practices rather than on deficits. Oster, Grier, Lightning, Mayan, and Toth (2014) associate deficit-focused discourse with generalizations about Indigenous peoples.

The school-based program from the case study moves away from deficitbased programs and redefines asset-based programs as responsibility-based. The reason for this comes from the local knowledge of the Anishinaabek community where the idea grew. If bimaadiziwin is a way of living a good life and is different from health as a status, then it makes sense to have the measures used in the program focus on responsibilities as actions rather than measures as things. Methodologically, this is challenging to measure. For this reason, the mixed methods approach assumed under the transformative paradigm is beneficial. Narrative approaches are often more effective at capturing action-based measures than quantitative measures. Mertens (2009) reflects on the use of narrative in evaluation via critical race theory (CRT). Here, narratives have the potential to add the voice of populations that have had their voices removed from them. Drawing on Solorzano and Yasso, Mertens (2009, p. 286-287) describes how personal stories, 
third-person stories, and composite stories all add increased perspective on the lived experiences of the people we work with.

Personal stories, or small stories, since the work of William Labov in the 1960s and 1970s, have made an important contribution to narrative analysis and sociolinguistics (Ingraham, 2016). Small stories, as defined by Bamberg and Georgakopoulou (2008), are the small, mundane narratives we tell in everyday conversation. Small stories are an example of non-literary discourse, which is used to articulate the day-to-day experiences of individuals. Within the larger model developed by Labonte and Torgerson (2005), small stories speak at the individual level and can be made into composites of a community level discourse. Small stories are not official perspectives but contain in them valuable local knowledge.

The second methodological assumption I work with is rooted in the increased call for Indigenous methodologies to be used in Indigenous research. Like many people, my first encounter with the concept of Indigenous research methodologies was through Linda Tuhiwai Smith's (1999) Decolonizing Methodologies. It was an assigned reading in my undergraduate program in Native Studies (now Indigenous Studies) at Trent University. Over the years, as I have continued my learning process, I have become concerned about discourses that create a divide between Indigenous and Western methods within the academy. Practical experience has suggested that the best way forward is through a process that allows for the decentring of power from one paradigm toward the development of beneficial and lasting relationships. Joseph P. Gone offers two important take-away points on this issue: he sees it unlikely that the recovery of remaining pre-contact epistemologies will be well suited for university-based knowledge production; and the adaptation or decolonizing of research methodologies can be considered as a "metis" approach rather than a dichotomy of Indigenous versus Western (Gone, 2019, pp. 51-52).

Practically, this has meant that partnerships between First Nations communities and university-based researchers/evaluators can act as a method for sharing skills and building capacity on both sides of the relationship. As one of my partners has joked about the use of the two-eyed seeing approach, an approach that incorporates Indigenous and Western knowledge, by saying "of course we look with two eyes. If you don't you bump into too many things." Her point was that we make fewer mistakes when we think more openly. I have learned to listen when she jokes because the lessons contained in humour are often important. This example demonstrates to me how small stories can be applied to understand the variety of communication styles that we encounter in our work, including humour.

\section{AXIOLOGICAL ASSUMPTIONS}

I will not spend much time on the axiological assumptions associated with the transformative paradigm. This principle is associated with respect, beneficence, and justice (Mertens, 2009, p. 49). My experience is that these principles are based in long-term, meaningful relationships. They develop when we stop seeing our 
partners as objects of study and open ourselves up to be learners. I have experienced the greatest roadblocks related to this element coming from the institutions where our non-community-based team members are located. Just as health can be read as a way a society should look, so can research ethics be a standardized way of dictating how an ongoing relationship should exist. That is not the act of decentring power.

\section{CONCLUSION}

By situating myself as a learner, I open myself to see the relationships between power, discourse, and the paradigms that are supported by them acting across levels of social structure. Social inequality creates conditions where some members of the population are left in a relative state of disadvantage. Cultural and language differences interact with power in order to maintain discursive forces that normalize one version of health over another. In the process of evaluation, we must be willing to identify how these factors influence the work that we do and to engage in evaluations that incorporate transformative assumptions which will allow us to push back against the existing power structures.

The steps that are available to us are tied to our own actions and our willingness to engage in meaningful, bidirectional learning. My experience has been that humility and empathy are tools that benefit the evaluator when we are working with Indigenous communities. By engaging in the process of listening and learning with our Indigenous relationships, we are better able to shift the paradigms by exposing powerful, normative discourses that may devalue a local way of knowing. As discussed in the case study, the local value of the in-school program was not the quantitative data easily explained to the general public. Instead, the real value to the community came in the form of the relationships, and the responsibilities inherent in those relationships, which make the program effective. From a community perspective, they were interested in how the program changed how youth behaved.

Finally, I have learned the valuable lesson of listening, thinking, and then acting in the process of moving from assumptions to applications. The application of critical approaches allows us to expose the invisible, normative aspects of our assumptions and develop applications with our community-based relationship. Applying a mixed methods approach, including narrative or discourse analysis, facilitates the development of a more complex and effective evaluation program.

\section{REFERENCES}

Bamberg, M., \& Georgakopoulou, A. (2008). Small stories as a new perspective in narrative and identity analysis. Text and Talk, 28(3), 377-396. https://doi.org/10.1515/ TEXT.2008.018

Baudrillard, J. (1983). Simulations. Los Angeles, CA: Semiotext(e).

Breau, S., Toy, B., Brown, M., Macdonald, R., \& Cooms, O. T. (2018). In the footsteps of Mackintosh and Innis: Tracking Canada's economic centre of gravity since the 
Great Depression. Canadian Public Policy, 44(4), 356-367. https://doi.org/10.3138/ cpp.2018-015

Crengle, S., Smylie, J., Kelaher, M., Lambert, M., Reid, S., Luke, J. . . \& Harwood, M. (2014). Cardiovascular disease medication health literacy among Indigenous peoples: Design and protocol of an intervention trial in Indigenous primary care services. BMC Public Health, 14, 714-721. https://doi.org/10.1186/1471-2458-14-714. Medline:25016481

Daniel, Y., \& Bondy, K. (2008). Safe schools and zero tolerance: Policy, program and practice in Ontario. Canadian Journal of Educational and Administrative Policy, 70, 1-20.

Farmer, P. (2004). An anthropology of structural violence. Current Anthropology, 45(3), 305-325. https://doi.org/10.1086/382250

Gone, J. P. (2019). Considering Indigenous research methodologies: Critical reflections by an Indigenous knower. Qualitative Inquiry, 25(1), 45-56. https://doi. org/10.1177/1077800418787545

Greene, R., \& Winkler, J. (2019). Collaborative and Proactive Solutions (CPS): A review of research findings in families, schools, and treatment facilities. Clinical Child and Family Psychology Review, 22(4), 549-561. https://doi.org/10.1007/s10567-019-00295-Z. Medline:31240487

Guba, E. G., \& Lincoln, Y. S. (1989). Fourth generation evaluation. Newbury Park, CA: Sage Publications.

Ingraham, C. (2016). The scope and autonomy of personal narrative. Written Communication, 34(1), 54-74. https://doi.org/10.1177/0741088316683147

International Health Conference. (2002). Constitution of the World Health Organization. 1946. Bulletin of the World Health Organization, 80(12), 983-984. https://apps.who.int/ iris/handle/10665/268688

Jacobs, D., Darnell, R., McKinley, G. P. (Forthcoming). Negotiating Good Development: Standards for Consultations in Making Standards Local. Graham, J. F., Holms, C., McDonald, F., and Darnell, R. (Eds). Vancouver, BC: University of British Columbia Press.

Keane, C. (1998). Globality and constructions of world health. Medical Anthropology Quarterly, 12(2), 226-240. Medline:9627924

Keller, E. F., \& Lloyd, E. A. (1992). Keywords in evolutionary biology. Cambridge, MA: Harvard University Press.

Kirmayer, L. J., Gone, J. P., \& Moses, J. (2014). Rethinking historical trauma. Transcultural Psychiatry, 51(3), 299-231. https://doi.org/10.1177/1363461514536358. Medline: 24855142

Labonte, R., \& Torgerson, R. (2005). Interrogating globalization, health and development: Towards a comprehensive framework for research, policy and political action. Critical Public Health, 15(2), 157-179. https://doi.org/10.1080/09581590500186117

Mertens, D. M. (2009). Transformative research and evaluation. New York, NY: The Guilford Press.

Mertens, D. M. (2013). What does a transformative lens bring to credible evidence in mixed methods evaluations? In D. M. Mertens \& S. Hesse-Biber (Eds.), Mixed methods and credibility of evidence in evaluation. New Directions for Evaluation, 2013(138), 27-35. 
Mertens, D. M., \& Wilson, A. T. (2012). Program evaluation theory and practice: A comprehensive guide. New York, NY: The Guilford Press.

Oster, R. T., Grier, A., Lightning, R., Mayan, M. J., \& Toth, E. L. (2014). Cultural continuity, traditional Indigenous language, and diabetes in Alberta First Nations: A mixed methods study. International Journal of Equity in Health, 13, 92-103. https://doi. org/10.1186/s12939-014-0092-4. Medline:25326227

Scriven, M. (2017). Empowerment evaluation 21 years later: There is much to admire about empowerment evaluations. Evaluation and Program Planning, 63, 138. https://doi. org/10.1016/j.evalprogplan.2016.10.004

Smith, L. T. (1999). Decolonizing methodologies: research and indigenous peoples. New York, NY: Zed Books.

Valentine, R. (2001). Nishnaabemwin reference grammar. Toronto, ON: University of Toronto Press.

Waapataneexkweew. (2018). Looking backward but moving forward: Honoring the sacred and asserting the sovereign in Indigenous evaluations. American Journal of Evaluation, 39(4), 343-568. https://doi.org/10.1177/1098214018790412

\section{AUTHOR INFORMATION}

Gerald McKinley is a medical anthropologist who specializes in the social determinants of mental health and Indigenous youth wellness in Ontario, Canada. Dr. McKinley is an Assistant Professor in the Schulich Interfaculty Program in Public Health where he utilizes ethnographic and archival research methodologies while working in partnership with First Nations communities. He is an active member of the Indigenous Youth Futures Partnership Program in partnership with the Sioux Lookout First Nations Health Authority. Dr. McKinley works to support communities through evaluations of their existing programs and is currently engaged in the program evaluations for programs funded under Jordan's Principle. 